\title{
21st Annual Institute for Healthcare Improvement (IHI) Scientific Symposium on Improving the Quality and Value of Health Care
}

\author{
Gareth Parry, Senior Scientist, Institute for Healthcare Improvement
}

\section{BACKGROUND}

Hosted by the Institute for Healthcare Improvement (IHI), the 21st Annual Scientific Symposium on Improving the Quality and Value of Health Care takes place on Monday, December 7, 2015, in Orlando, Florida, USA. The Scientific Symposium aimed to attract high quality, scientific work, focused on the improvement of health and health care. The symposium also aimed to foster dialog and share learning among participants. The day features keynote speakers, methods sessions, poster presentations and oral presentations. The 32 oral presentations were selected from 191 abstract submissions, through a process peer review process, that ensured each abstract was reviewed by four reviewers. For those authors that gave permission, the abstracts of the selected oral presentations are published below.

\section{ACKNOWLEDGEMENTS}

On behalf of the Institute for Healthcare Improvement, the hosts would like to thank the individuals whose contributions have made the 21st Annual Scientific Symposium on Improving the Quality and Value of Health Care a success. Particular thanks are due to the abstract reviewers - Amrita Dasgupta, Amy Reid, Barry Appleton, Brant Oliver, Don Goldmann, Gareth Parry, Jane Roessner, Jon Finkelstein, Kedar Mate, Linson Naval, Lisa Hirschhorn, Mara Laderman, Marianne McPherson, Nana Twum-Danso, Pierre Barker, Sandy Cohen, Sharon Muret-Wagstaff, Wynne Norton, A.J. Layon, Andrew Steele, Angela Green, Darren Klugman, David Mosen, Denise Remus, Ezequiel Garcia Elorrio, Lucy Pereira-Argenziano, Jackie Valentine, Jaleh Shafii, Keith Mann, M Abid Shah, Mary Coleman, Nina Rauscher, Omar Hasan, Rick McClead, Rob Payne, Sandip Godambe, Tina C. Foster, Tracy West-Grubb, and Treiste Newton - without whose efforts we could not accomplish a Symposium of this quality. Thanks, as well, are due all those who were willing to submit their research for review. Last, but certainly not least, we thank our program committee members - Don Goldmann, Pierre Barker, Amy Reid, Beth McGlynn, Brant Oliver, Wynne Norton, Lisa Hirschhorn, Rohit Ramaswamy, Brian Mittman, David Nash, Lloyd Provost, Nana Twum-Danso, Jonathan Finkelstein, Carolyn Clancy, Uma Kotagal, and Marianne McPherson - who provided valuable insight and guidance to make this year's Symposium as enriching as possible; and Carly Underwood, Jason Reed and Linson Naval who have dedicated countless hours to the development of this year's program. 